\title{
Síndrome de Guillain-Barré recurrente asociado con infección por SARS-CoV-2
}

\author{
Recurrent Guillain-Barré syndrome associated with SARS-CoV-2 infection \\ Luis Gerardo Domínguez Carrillo, ${ }^{*}$ José Luis Alcocer Maldonado, ${ }^{\neq}$ \\ Luis Gerardo Domínguez Gasca, § José Gregorio Arellano Aguilar"
}

Citar como: Domínguez CLG, Alcocer MJL, Domínguez GLG, Arellano AJG. Síndrome de Guillain-Barré recurrente asociado con infección por SARS-CoV-2. Acta Med GA. 2021; 19 (4): 554-557. https://dx.doi.org/10.35366/102546

\section{Resumen}

Introducción: El síndrome de Guillain-Barré (SGB) generalmente se considera monofásico, pero las recurrencias ocurren en un subgrupo de pacientes con tasa de recurrencia de 1 a $6 \%$. Con el advenimiento de la pandemia de SARS-CoV-2 los reportes del SGB se han incrementado, además de surgir SGB recurrente. Caso clínico: Masculino de 46 años, que seis años atrás presentó SGB asociado con Campylobacter jejuni, con recuperación ad integrum, y acude en esta ocasión con recurrencia del SGB, pero con diferencia de ser más severa la sintomatología y con carácter descendente, a diferencia del primer episodio. En ambas ocasiones fue atendido por el mismo equipo médico, manejado de manera similar, logrando recuperación más tardía en el segundo episodio. Conclusiones: Aunque aún existe controversia en la literatura, el SGB recurrente se presenta en personas más jóvenes y los cuadros pueden ser más severos en los episodios subsecuentes.

Palabras clave: Síndrome de Guillain-Barré, recurrencias, SARS-CoV-2.

\section{INTRODUCCIÓN}

El síndrome de Guillain-Barré (SGB) es una polirradiculoneuropatía aguda de rápida evolución que se presenta típicamente con debilidad muscular bilateral y parestesias, en asociación con reflejos tendinosos profundos ausentes o disminuidos. La gravedad de la debilidad en los casos

\section{Abstract}

Introduction: Guillain-Barré syndrome (GBS) is generally considered monophasic, but recurrences occur in a subgroup of patients with a recurrence rate of 1 to $6 \%$. With the advent of the SARS-CoV-2 pandemic, reports of GBS have increased, in addition to recurrent GBS. Clinical case: 46-year-old male, who six years ago presented GBS associated with Campylobacter jejuni, with ad integrum recovery; in the last year he presented a GBS recurrence, but with a difference of being more severe and with a descending character, unlike from the first episode. On both occasions, he was treated by the same medical team, managed in a similar way, achieving a later recovery in the second episode. Conclusions: Although there is still controversy in the literature, recurrent GBS occurs in younger people, and the pictures can be more severe in subsequent episodes.

Keywords: Guillain-Barré syndrome, recurrences, SARSCoV-2.

de SGB varía desde una leve debilidad hasta una parálisis total que puede provocar la muerte. La tasa de incidencia media anual del SGB se sitúa entre 0.4 y cuatro casos por 100,000 habitantes. ${ }^{1}$ Las personas de cualquier edad están en riesgo; sin embargo, la incidencia es mucho mayor entre los ancianos. El SGB generalmente se considera monofásico, pero las recurrencias, de acuerdo con el estudio
* Especialista en Medicina de Rehabilitación. Catedrático de la Facultad de Medicina de León, Universidad de Guanajuato. México.

* Neurocirujano. Catedrático de la Facultad de Medicina de León, Universidad de Guanajuato. México.

$\S$ Ortopedista. Cirugía Articular. División de Cirugía. Hospital Angeles León. León, Guanajuato, México.

" Especialista en Medicina Interna. División de Medicina. Hospital Angeles León. León, Guanajuato, México.
Correspondencia:

Acad. Dr. Luis Gerardo Domínguez Carrillo

Correo electrónico: Igdominguez@hotmail.com

Aceptado: 11-03-2021.

www.medigraphic.com/actamedica

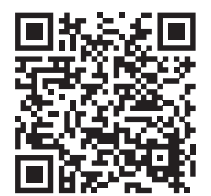


de Gunatilake y colaboradores, ${ }^{2}$ ocurren con una tasa de 1 a $6 \%$. El síndrome de Guillain-Barré recurrente (SGBR) se define de acuerdo con el estudio de Kuitwaard y su equipo $^{3}$ como dos o más episodios que cumplieron los criterios del National Institute of Neurologic Disorders and Stroke (NINCDS) para SGB, ${ }^{4}$ con un tiempo mínimo entre episodios de dos meses (cuando existe recuperación completa entre ellos) o cuatro meses (cuando la recuperación es parcial); no obstante, el reporte de Mossberg y colegas ${ }^{5}$ menciona 15 casos en los cuales tuvieron de dos a siete episodios de recurrencia que se produjeron a intervalos irregulares durante 17 años. En general, los síntomas neurológicos de los episodios posteriores al primer ataque son a menudo similares, sin embargo, la gravedad de los síntomas y la naturaleza de las infecciones precedentes varían con el segundo episodio. A su vez, este grupo de pacientes se caracteriza porque la mayoría son menores de 30 años.

La nueva enfermedad por coronavirus 2019 (COVID-19), causada por el síndrome respiratorio agudo severo coronavirus 2 (SARS-CoV-2), se documentó por primera vez en diciembre de 2019 en Wuhan, China. Aunque COVID-19 conduce predominantemente a síntomas respiratorios, también se han informado varios síntomas neurológicos, como cefalea, síncope, mialgia, anosmia y ageusia. Investigaciones recientes han demostrado que COVID-19 se ha asociado con una amplia gama de neuropatías inmunes, incluido el SGB y el empeoramiento de la polirradiculopatía desmielinizante inflamatoria crónica (PDIC). Al respecto McDonnell y su grupo, ${ }^{6}$ Virani y colaboradores ${ }^{7}$ y Abu-Rumeileh y sus colegas ${ }^{8}$ reportaron los primeros casos de SGBR asociado con COVID-19; por nuestra parte, al presentarse un paciente con SGBR (manejado por el mismo equipo médico en ambos episodios con diferencia de seis años entre ambos), siendo este último asociado con infección por COVID-19 (hasta donde sabemos), es el primer caso en León, Guanajuato, México, siendo el motivo de esta comunicación.

\section{CASO CLÍNICO}

Primer episodio. Masculino de 40 años, músico, que inició en febrero de 2014 con cuatro días de evacuaciones diarreicas, agregándose al quinto día paresia simétrica de miembros inferiores de inicio distal en pies, con carácter ascendente en las cuatro extremidades. Con diagnóstico de síndrome de Guillain-Barré asociado con Campylobacter jejuni, el líquido cefalorraquídeo mostró disociación albuminocitológica, se reportaron anticuerpos GD1b-lgG y anti-GQ1b positivos; la resonancia magnética de encéfalo normal; el coprocultivo mostró Campylobacter jejuni. Se le manejó con inmunoglobulina intravenosa (IgIV); permaneció hospitalizado por siete días y derivado a rehabilitación, siendo dado de alta a las 12 semanas, con fuerza muscular $5 / 5$ para las cuatro extremidades.

Segundo episodio. Lo inicia a los 46 años, al presentar en septiembre de 2020 fiebre de $38.3{ }^{\circ} \mathrm{C}$, acompañado de tos seca, malestar general y cefalea; dos días después se agrega evacuaciones líquidas 6-8/día; 24 horas después presentó paresia simétrica de las cuatro extremidades, pero en esta ocasión, con carácter descendente, iniciando en cintura escapular y pélvica, que en un lapso de 16 horas avanzó a manos y pies, por lo que acudió a urgencias. Fue valorado por neurocirugía, quien lo hospitalizó con diagnóstico de síndrome de Guillain-Barré recurrente, la prueba de reacción en cadena de la polimerasa (PCR) para COVID-19 en naso- y orofaringe fue positiva; el líquido cefalorraquídeo (LCR) mostró disociación albuminocitológica, se reportaron anticuerpos GD1b-IgG y anti-GQ1b positivos, la prueba PCR para COVID-19 en LCR resultó negativa y la resonancia magnética de encéfalo normal. Se manejó con IgIV; permaneció hospitalizado 14 días y derivado a rehabilitación. Al momento de realizar este reporte a las 12 semanas, el paciente camina con ayuda de bastones, siendo independiente en las actividades de la vida diaria; y con programa de fortalecimiento muscular a cinturas escapular y pélvica en domicilio.

\section{DISCUSIÓN}

La relación de afecciones del sistema nervioso central y periférico con los virus, en especial con los coronavirus, no es nueva, los miembros de la familia Coronaviridae, especialmente del género $\beta$ como el caso de los virus del síndrome respiratorio agudo severo (SARS-CoV-1), ${ }^{9}$ en 2002-2003, originaron reportes sobre pacientes con polineuropatía, enfermedad cerebrovascular isquémica y encefalitis; al igual que el síndrome respiratorio del Medio Oriente (MERS-CoV) ${ }^{10}$ que en 2009 dio pie a los reportes de casos con polineuropatía, parálisis, convulsiones y alteraciones de la conciencia. La aparición a finales del 2019 del SARS-CoV-2 ha originado una verdadera avalancha de información, no sólo de afección pulmonar, sino de otros aparatos y sistemas, entre ellos el sistema nervioso central (SNC) y periférico, como ejemplo, en el presente año, Mao y su equipo, ${ }^{11}$ en Wuhan (origen geográfico de la pandemia), describieron un grupo de 214 pacientes hospitalizados con SARS-CoV-2; del cual 36.4\% presentó alguna manifestación neurológica clasificada como afectación central (24.8\%), periférica (10.7\%) y musculoesquelética (10.7\%). El primer caso de síndrome de Guillain-Barré relacionado directamente con SARS-CoV-2 fue reportado por Zhao y colaboradores. ${ }^{12}$ Por otra parte, Toscano y su grupo, ${ }^{13}$ en Italia, reportaron cinco pacientes con síndrome de Guillain-Barré como complicación neurológica de infec- 
ción por SARS-CoV-2 con un intervalo desde los síntomas respiratorios hasta los síntomas del síndrome de 5-10 días.

EI SARS-CoV-2 es un beta-coronavirus que puede invadir al sistema nervioso, reportes recientes sugieren que los coronavirus pueden utilizar el transporte axonal, dando lugar a presencia de neuropatología. ${ }^{1}$ Respecto a afecciones de nervios periféricos relacionadas con infección por COVID-19, parece estar implicada una respuesta inflamatoria desencadenada por la presencia de virus, orientando a que la fisiopatogenia se relaciona con mecanismos inmunológicos capaces de producir daño al sistema nervioso periférico. ${ }^{14} \mathrm{El}$ antecedente de un cuadro infeccioso precede a los síntomas en 43 a $60 \%$ de los casos, se le ha relacionado a Campylobacter jejuni (21\%), Haemophilus influenzae (8\%), citomegalovirus (3\%) y Mycoplasma pneumoniae (3\%), así como la aplicación de vacunación. ${ }^{15}$ En más de $90 \%$ de los pacientes con SGB se detectan anticuerpos anti-GQ1b y los títulos de IgG son mayores al inicio del cuadro. Histopatológicamente se observa desmielinización e infiltración mononuclear de los nervios. La instauración del cuadro suele ser aguda en horas o días, siendo la última la más frecuente reportada. El análisis del líquido cefalorraquídeo puede mostrar una disociación albuminocitológica, aunque al inicio puede ser normal, lo que concuerda con los hallazgos previamente reportados. Los estudios de conducción nerviosa demuestran la afección desmielinizante. ${ }^{16}$

El síndrome de Guillain-Barré recurrente ${ }^{17}$ (SGBR) se define como dos o más episodios de SGB que tienen $\geq 4$ meses entre episodios sin recuperación completa, o $\geq 2$ meses entre episodios si el paciente presenta una recuperación completa o casi completa. El SGBR ocurre en 1 a $6 \%$ de los pacientes con SGB diagnosticado previamente, y los pacientes con SGBR a menudo tienen una enfermedad previa con inicio rápido de síntomas; los síntomas suelen ser similares incluso con diferentes desencadenantes virales. Los criterios diagnósticos del SGB incluyen debilidad motora progresiva en al menos una extremidad, que puede variar desde debilidad hasta parálisis completa y arreflexia.

Con relación al SGBR, en el reporte de Das y colegas, ${ }^{18}$ sobre 11 casos de SGBR, con edad de entre cinco y 40 años (seis niños), ocho presentaron dos ataques, dos pacientes tres ataques y uno más tuvo cuatro episodios. El intervalo entre ataques osciló entre cuatro meses y 10 años (media de 39.5 meses). La gravedad de los diferentes episodios no se relacionó con el número de recurrencias. Los estudios de conducción nerviosa fueron consistentes con neuropatía desmielinizante; ocho pacientes se recuperaron completamente después del ataque inicial y tres tuvieron paresia de dorsiflexores de tobillo persistente a los seis meses de seguimiento; después del segundo ataque, cuatro pacientes se recuperaron y los siete restantes presentaron la paresia antes mencionada; después del tercer ataque, un paciente se recuperó completamente y los otros dos tenían un déficit residual en forma de debilidad en el agarre y caída del pie, lo que indica que existe tendencia a acumular déficits neurológicos con una frecuencia creciente con cada nuevo episodio.

Con respecto al LCR en pacientes con SGB y SARSCoV-2, en la revisión sistemática efectuada por Trujillo y su equipo, ${ }^{19}$ conjuntando un total de 30 casos de SGB asociados con SARS-CoV-2, todos los casos mostraron resultados negativos de PCR en LCR. Sin embargo, también se han planteado como posibles mecanismos por los cuales el SARS-CoV-2 puede causar daños neurológicos el anclaje del virus a la enzima convertidora de angiotensina (ACE2) en la barrera hematoencefálica, facilitando su ingreso al sistema nervioso central; así como también se ha propuesto que existen vías de diseminación neural retrógrada, transcribal y hematógena.

En relación con la resonancia magnética, la encefalitis es una complicación menos frecuentemente descrita en la infección por el nuevo SARS-CoV-2, así como en otros coronavirus y virus neurótropos, y se produce tanto por acción directa del virus sobre el sistema nervioso central como por un mecanismo inmunomediado, como es el caso de las encefalitis virales parainfecciosas. Por tanto, es posible que no se detecte el virus causante en el líquido cefalorraquídeo. En el caso de las encefalitis parainfecciosas, en la resonancia magnética se pueden llegar a observar lesiones perivasculares multifocales y lesiones desmielinizantes, mientras que las lesiones cerebrales producidas por las encefalitis víricas pueden afectar el lóbulo temporal, el tálamo, los ganglios basales, el cerebelo y el tronco del encéfalo ${ }^{20}$ o solamente ligeros realces leptomeníngeos a nivel troncoencefálico y médula cervical; sin embargo, en el SGB la resonancia magnética suele ser normal. ${ }^{21}$

Cuando se llega al diagnóstico de SGBR, el diagnóstico diferencial debe incluir a: 1) el síndrome de Guillain-Barré con fluctuaciones (SGBF) relacionadas con el tratamiento y 2) la polineuropatía desmielinizante inflamatoria crónica (PDIC); el primero se presenta en $6-16 \%$ de los pacientes con SCB, se le define como un deterioro significativo dentro de los dos meses posteriores al inicio de la enfermedad después de una mejoría o estabilización postratamiento. En estos casos, la repetición de inmunoglobulina o plasmaféresis mejora la sintomatología; en el segundo caso la PDIC se caracteriza porque la progresión de la debilidad dura más de ocho semanas seguida de un curso crónico, llegando a ser monofásica, progresiva, remitente recurrente. El tratamiento difiere, ya que la PDIC puede tratarse con inmunoglobulina o terapia inmunosupresora, mientras que el SGB y el SGBF no muestran una respuesta a la terapia inmunosupresora, pero tienen una buena respuesta a la 
inmunoglobulina o plasmaféresis. Otra característica distintiva es que en el SGBR, es a menudo de cuatro semanas, mientras que la PDIC por definición progresa durante al menos dos meses. No obstante, se puede considerar que el SGBR y la PDIC pueden ser parte del espectro y representar una gama de polirradiculopatías desmielinizantes inflamatorias en lugar de diagnósticos distintos. ${ }^{22}$

\section{CONCLUSIONES}

El advenimiento de la pandemia por COVID-19 ha enfrentado al médico con una enfermedad de carácter sistémico, que puede llegar a afectar al sistema nervioso central y periférico como las polirradiculopatías, así como ser causa de recurrencias de las mismas.

\section{REFERENCIAS}

1. Andary MT, Oleszek JL, Maurelus K, White-McCrimmon RY, Klein MJ. Guillain-Barre syndrome. Medscape. 2020. Available in: http:// emedicine.medscape.com/article/315632-overview\#a0156

2. Gunatilake SS, Gamlath R, Wimalaratna H. An unusual case of recurrent Guillain-Barré syndrome with normal cerebrospinal fluid protein levels: a case report. BMC Neurol. 2016; 16 (1): 161. doi: 10.1186/s12883-016-0687-z.

3. Kuitwaard K, van Koningsveld R, Ruts L, Jacobs BC, van Doorn PA. Recurrent Guillain-Barré syndrome. J Neurol Neurosurg Psychiatry. 2009; 80 (1): 56-59. doi: 10.1136/jnnp.2008.156463.

4. Fokke C, van den Berg B, Drenthen J, Walgaard C, van Doorn PA, Jacobs BC. Diagnosis of Guillain-Barré syndrome and validation of Brighton criteria. Brain. 2014; 137 (Pt 1): 33-43.

5. Mossberg N, Nordin M, Movitz C, Nilsson S, Hellstrand K, Bergstrom T et al. The recurrent Guillain-Barré syndrome: a long-term populationbased study. Acta Neurol Scand. 2012; 126 (3): 154-161. doi: 10.1111/j.1600-0404.2012.01667.x.

6. McDonnell EP, Altomare NJ, Parekh YH, Gowda RC, Parikh PD, Lazar MH et al. COVID-19 as a trigger of recurrent Guillain-Barré syndrome. Pathogens. 2020; 9 (11): 965. doi: 10.3390/pathogens9110965.

7. Virani A, Rabold E, Hanson T, Haag A, Elrufay R, Cheema T et al. Guillain-Barré Syndrome associated with SARS-CoV-2 infection. IDCases. 2020; 20: e00771.

8. Abu-Rumeileh S, Garibashvili T, Ruf W, Fangerau T, Kassubek J, Althaus $\mathrm{K}$ et al. Exacerbation of chronic inflammatory demyelinating polyneuropathy in concomitance with COVID-19. J Neurol Sci. 2020; 418: 117106.

9. Chao CC, Tsai LK, Chiou YH, Tseng MT, Hsieh ST, Chang SC et al. Peripheral nerve disease in SARS: report of a case. Neurology. 2003; 61 (12): 1820-1821.

10. Stainsby B, Howitt S, Porr J. Neuromusculoskeletal disorders following SARS: a case series. J Can Chiropr Assoc. 2011; 55 (1): 32-39.

11. Mao L, Wang M, Chen S, He Q, Chang J, Hong C et al. Neurological manifestations of hospitalized patients with COVID-19 in Wuhan, China: a retrospective case series study. MedRxiv. 2020. doi: 10.1101/2020.02.22.20026500.

12. Zhao H, Shen D, Zhou H, Liu J, Chen S. Guillain-Barré syndrome associated with SARS-CoV-2 infection: causality or coincidence? Lancet Neurol. 2020; 19 (5): 383-384.

13. Toscano G, Palmerini F, Ravaglia S, Ruiz L, Invernizzi P, Cuzzoni MG et al. Guillain-Barré syndrome associated with SARS-CoV-2. N Engl J Med. 2020; 382 (26): 2574-2576. doi: 10.1056/NEJMc2009191.

14. Mao L, Jin H, Wang M, Hu Y, Chen S, He Q et al. Neurologic manifestations of hospitalized patients with coronavirus disease 2019 in Wuhan, China. JAMA Neurol. 2020; 77 (6): 683-690.

15. Baxter R, Lewis N, Bakshi N, Vellozzi C, Klein NP; CISA Network. Recurrent Guillain-Barre syndrome following vaccination. Clin Infect Dis. 2012; 54 (6): 800-804. doi: 10.1093/cid/cir960.

16. Taly AB, Gupta SK, Anisya V, Shankar SK, Rao S, Das KB et al. Recurrent Guillain Barre' syndrome: a clinical, electrophysiological and morphological study. J Assoc Physicians India. 1995; 43 (4): 249-252.

17. Grand'Maison F, Feasby TE, Hahn AF, Koopman WJ. Recurrent Guillain-Barré syndrome. Clinical and laboratory features. Brain. 1992; 115 (Pt 4): 1093-1106. doi: 10.1093/brain/115.4.1093.

18. Das A, Kalita J, Misra UK. Recurrent Guillain Barre' syndrome. Electromyogr Clin Neurophysiol. 2004; 44 (2): 95-102.

19. Trujillo Gittermann LM, Valenzuela Feris SN, von Oetinger Giacoman A. Relación entre COVID-19 y síndrome de Guillain-Barré en adultos. revisión sistemática. Neurología. 2020; 35 (9): 646-654. doi: 10.1016/j.nrl.2020.07.004.

20. Serrano-Serrano B, López-Hernández N, Dahl-Cruz F, Elvira-Soler E, Díaz-Marín C. Encefalitis multifocal como manifestación neurológica de la infección por COVID-19. Rev Neurol. 2020; 71: 351-352. doi: 10.33588/rn.7109.2020226.

21. Esteban Molina A, Mata Martínez M, Sánchez Chueca P, Carrillo López A, Sancho Val I, Sanjuan-Villarreal TA. Síndrome de Guillain-Barré asociado a infección por COVID-19. Med Intensiva. 2020; 44 (8): 513-514. doi: 10.1016/j.medin.2020.04.015.

22. Dyck PJB, Tracy JA. History, diagnosis, and management of chronic inflammatory demyelinating polyradiculoneuropathy. Mayo Clin Proc. 2018; 93 (6): 777-793. 